\section{Más allá de Freud. Una historia del pensamiento psicoanalítico moderno}

\author{
Autores: Stephen A. M itchell, \\ $M$ argaret Black
}

Editorial: Herder, Barcelona, 2004, 429 páginas.

Todo texto sobre la historia del psicoanálisis debe justificarse de modo convincente porque la cantidad de literatura disponible es ya inundatoria. En cualquier caso, ambos autores nos son conocidos desde hace tiempo porque se han dedicado al tema de modo serio y con acuciosidad, aunque quizás no de una manera especialmente creativa. Son buenos artesanos que manejan con habilidad el oficio desde el punto de vista y supuestos americanos y, en esta oportunidad, lo vuelven a realizar con atributos y resultados similares. En una frase, es un libro dedicado a aquellos que se inician y empiezan a batallar con los diferentes autores y corrientes del psicoanálisis desde Freud hasta nuestros días apoyándose en casos clínicos sencillos que son útiles, en algunas oportunidades, para ejemplificar lo que se está tratando de conceptuar de modo teórico.

Se divide en nueve capítulos de similar longitud y profundidad y las figuras elegidas son tanto las clásicas como los psicoanalistas actuales: Freud, Anna Freud, Harry Stack Sullivan, M elanie Klein, Winnicott, Fairbairn, Erikson, Kohut, Kernberg, Schafer, Loewald, Lacan, por nombrar los más detalladamente estudiados. En general se tiende a exponer cada doctrina y luego a compararla en sus aspectos teóricos y clínicos con las restantes, especialmente con la teoría "clásica", que es la denominación que ellos utilizan para referirse a Freud o la Psicología del Yo, según el caso. Lo que no queda completamente aclarado es el criterio de selección utilizado para escogerlos, por ejemplo en los casos de Sullivan y Erikson. ¿Son de tanta trascendencia o singularidad sus aportes como para dedicarles sendos capítulos?

Los méritos del libro están implícitos en lo expuesto hasta aquí: no sesgado desde su propia concepción, tratamiento de las figuras más decisivas dejando fuera pocas de relevancia reconocida, conocimiento tanto del tema como ambiente del psicoanálisis institucional, intento de comprensión de cada psicoanalista desde su propio interior, sorteo del fanatismo de parroquia de cada doctrina acudiendo a la historia del mismo psicoanálisis como recordatoria que cada escuela que parecía resolver todos los dilemas clínicos era una ilusión propia del momento.

Paradójicamente el que sale peor parado es Freud mismo. A lo que nos referimos es que, en parte por darse por supuestas muchas de sus contribuciones, se pasa por encima de él sin introducirse en los matices y sutilezas peculiares a su modo de pensar y se aborda rápidamente los otros analistas que habrían "superado" sus carencias, el "más allá". El "duelo" por Freud es un asunto delicado: o se le endiosa o se lo envilece, o se lo coloca como la roca que nunca podrá ser removida o se lo saca como una pieza cualquiera de un puzzle que puede seguir funcionando sin él - un significante más. M itchell y Black no llegan a ninguno de los dos extremos pero Freud queda finalmente deslavado, sin una rica consistencia interna, una suerte de máscara pintada con colores vivos pero máscara al fin. ¿Se produjo lo que el mismo Freud predijo sobre su posible futuro al interior de la civilización americana, por lo que él siempre desconfió de ella?

El continente europeo está considerado -lo que es un avance-, pero con sabor a conocimiento libresco antes que vívidamente meditado, debatido y digerido. Tanto la así llamada Escuela Británica como Lacan se exponen sin penetrar nunca ni en el capital clínico que está sustentando sus visiones ni en sus revolucionarias propuestas. Uno se pregunta por qué el psicoanálisis inglés ha experimentado tanta resistencia en los Estados Unidos y suponemos que la respuesta es particularmente compleja, más allá de la conoci- 
da sentencia británica, de que los dos países se parecen mucho salvo en el idioma. Queda claro, por lo menos, que el énfasis en la pulsión agresiva y en los objetos internos innatos del bebé provoca un marcado escozor al otro lado del Atlántico. ¿Es el escepticismo de Freud que late detrás de ambas asertos lo que desencadena una repulsa visceral? ¿Es su concepción del hombre que no tolera ilusiones de ningún tipo a pesar de que todos las necesitamos desesperadamente? Lacan es, como es solito, un caso excepcional. Los autores no logran coger su pensamiento y lo declaran abiertamente aunque, agregan, se esfuerzan y tratan de hacerlo entendible de acuerdo a sus posibilidades. Son honestos y no se quedan en la descalificación fácil y altanera, lo que no se puede decir, a veces, del vocinglero analista parisino.

Ya hicimos mención que se acude a viñetas clínicas para mostrar en vivo cómo se pueden abordar los pacientes cuando se emplean distintos modelos. La debilidad del texto exhibe aquí una mancha gruesa que echa a perder el conjunto. La mayoría de las veces son banales y, en otras, forzadas 0 aún equivocadas por lo simplistas. Es en el momento de abordar a Lacan cuando se hace más palmaria la falta de empatía y aún de perspicacia frente al discutido mandarín francés, lo que quizás les habría valido más a Mitchell y
Black no intentar aplicarlo en una historia concreta.

Los dos capítulos finales se refieren a las controversias. Las que se ocupan de la teoría, aluden a las conocidas aporías entre trauma/fantasía, conflicto/desarrollo, género/sexualidad, empirismo/ hermenéutica: todas interesantes pero insatisfactorias sus respuestas, porque quedan en las manidas discusiones sin un aporte novedoso 0 , cuando menos, desatendido e inesperado. Las que se adentran en la técnica, tratan las alternativas pasado/presente, interpretación/relación, transferencia/contratransferencia: se puede repetir lo recién dicho, no mueven al lector a interesarse ni menos a cuestionarse por permanecer en el nivel informativo.

¿Se puede prescindir del libro? Evidentemente, aunque se lo pueda recomendar a los interesados en tener una visión de conjunto del psicoanálisis. ¿Es una obra para ser leída después de almuerzo, como solía decir Kierkegaard? Sí, pero más de alguien necesitará refrescar sus conocimientos más allá de los novatos ávidos de penetrar en los senderos de los discípulos de Freud. ¿Está "más allá" de Freud? Lo dudamos.

Gustavo Figueroa C. 